\title{
Control of nanocrystal surface defects for efficient charge extraction in polymer-ZnO photovoltaic systems
}

SeungJin Han, A. A. D. T. Adikaari, K. D. G. I. Jayawardena, N. A. Nismy, and S. Ravi P. Silva*

Advanced Technology Institute

University of Surrey,

Guildford, GU2 7XH, UK

E-mail: s.silva@ surrey.ac.uk

Keywords: hybrid photovoltaics, zinc oxide, charge trapping

Solution processable photovoltaic devices based on an organic donor (D) and organic/inorganic acceptor (A) offers promise for development of low cost, light weight flexible energy sources. ${ }^{[1-2]}$ The performance of such devices (which have recently exceeded power conversion efficiencies of $7 \%^{[3]}$ ) is based on (1) the generation of bound electron-hole pairs (excitons) upon photoexcitation, (2) the dissociation of these excitons generated within the exciton diffusion length from the D-A interface (3) transportation of the free holes and electrons and (4) extraction of these charges at the anode and cathode respectively. While organic semiconductors are commonly used as the donor, ${ }^{[1-2]}$ fullerene derivatives ${ }^{[4-5]}$, n-type conjugated polymers $^{[6]}$ or inorganic nanostructures ${ }^{[7-8]}$ have been employed as acceptors. The potential advantage in the use of inorganic systems compared to the more widely used organic materials includes a high dielectric constant which facilitates effective exciton dissociation by reducing Coulombic interaction between the electron and the hole in an exciton as well as high carrier mobility. ${ }^{[7]}$ Among the inorganic materials systems widely studied, $\mathrm{ZnO}$ with its wide (bulk) band gap of $\sim 3.4 \mathrm{eV},{ }^{[9]}$ high electron mobility ${ }^{[10]}$ combined with the capability to form nanocrystallites at low temperatures through the use of metallorganic precursors ${ }^{[11]}$ 
allows it to be incorporated into organic donors that are known only to withstand low temperature annealing processes. ${ }^{[12]}$

Initial investigations on hybrid organic/inorganic photovoltaic systems focused on the addition of quantum dots, nanorods, multipods and nanoparticles into the organic donor. ${ }^{[13]}$ However, difficulty in identification of a suitable solvent for accommodating both the organic and inorganic components as well as the lack of a bicontinous network upon spin casting the hybrid mixture led to poor device efficiencies. ${ }^{[14-16]}$ In order to overcome the above technical difficulties, Beek et al ${ }^{[17]}$ proposed the use of diethyl zinc (DEZ), a molecular precursor that is readily soluble in organic media and converts to $\mathrm{ZnO}$ upon exposure to moisture at temperatures compatible with organic photovoltaic device fabrication. Since then, the use of DEZ has led to several reports on $\mathrm{ZnO}$ incorporated organic-inorganic hybrid photovoltaics. ${ }^{[7,}$ ${ }^{18-20]}$ In addition to the above mentioned advantages, the non-formation of $\mathrm{ZnO}$ at room temperature compared to other zinc containing metallorganic precursors ${ }^{[21]}$ as well as the possibility of forming a bicontinous network ${ }^{[7]}$ makes the use of DEZ an attractive route towards forming hybrid organic/inorganic photovoltaic cells. In addition to changing the nature through which the acceptor phase is incorporated, recent investigations have also focused on the use of modified organic donors for inorganic acceptor (Table S1). However as of present, efficiencies comparable to hybrid systems prepared using rr-P3HT and DEZ based $\mathrm{ZnO}$ is yet to be achieved.

Despite the advantages noted above, as well as the improved performance over devices prepared by adding $\mathrm{ZnO}$ nanocrystals $(\mathrm{S} 2)^{[22]}$, the efficiencies reported for hybrid devices using DEZ remain poor in comparison to devices incorporating fullerene based acceptors. This necessitates the need for improved understanding of exciton generation and dissociation, charge transport and subsequent charge extraction at the contacts in such hybrid systems before large scale deployment of the technology can be considered. In the work reported here, the steady-state photoluminescence (PL), optical absorption spectroscopy and current density 
- voltage (J-V) characteristics of the regio-regular poly (3-hexylthiophene) (rr-P3HT):ZnO DA hybrid system is analysed. These results are correlated with the humidity levels used to form the $\mathrm{ZnO}$ nanostructure in order to elucidate the role of surface defects on $\mathrm{ZnO}$ nanostructures and the disruption of the crystallinity of rr-P3HT.

The optical absorption spectra obtained for $80 \mathrm{~nm}$ thick rr-P3HT and rr-P3HT:ZnO composite systems are shown in Figure 1 (a). The crystalline nature of rr-P3HT leads to three vibronic features in wavelength range of 400 to $650 \mathrm{~nm}$ in its absorption spectrum. The vibronic features at $\sim 512$ and $560 \mathrm{~nm}$ corresponds to intrachain $\pi-\pi^{*}$ absorptions while the shoulder peak at $\sim 607 \mathrm{~nm}$ is attributed to the inter-chain interactions in the crystalline polymer. ${ }^{[23]} \mathrm{A}$ decrease in the relative intensity of the shoulder peak at the $607 \mathrm{~nm}$ to the peak at $561 \mathrm{~nm}$ is observed upon the introduction of $\mathrm{ZnO}$ into rr-P3HT indicating a decrease in the rr-P3HT inter-chain interaction. ${ }^{[24]}$ However, the intensity ratio (607 nm / $561 \mathrm{~nm}$ peak intensity) appears to be independent of the relative humidity employed (3 - 40\%) (Table S3) indicating little or no increase in disorder upon exposure to higher moisture levels. In addition to the decrease in the relative intensity mentioned above, the onset of the absorption at $\sim 607 \mathrm{~nm}$ is also observed to be blue shifted in comparison to the pristine rr-P3HT sample for all humidity levels analysed in this work. Previously reported work on organic systems incorporating fullerene derivatives have attributed such blue shifts to the reduction in the $\pi$-conjugation lengths of rr-P3HT as a result of conformational chain defects (such as twisting or disruption of the planer nature of rr-P3HT) induced by the inclusion of fullerene derivatives. ${ }^{[25]}$ As the formation of the $\mathrm{ZnO}$ acceptor phase is observed to lead to a disorder in the donor phase, a higher peak width for the pristine rr-P3HT can be discarded as a possible explanation for the apparent blue shift. As such, the observed blue shift is attributed to the decrease in the conjugation length as a result of the formation of an interpenetrating D-A networks during the formation of $\mathrm{ZnO}$. While such an interpenetrating network is likely to lead to a more efficient 
exciton dissociation process, the disorder introduced into the organic phase is expected to be detrimental to the charge transport in the $\mathrm{D}$ phase.
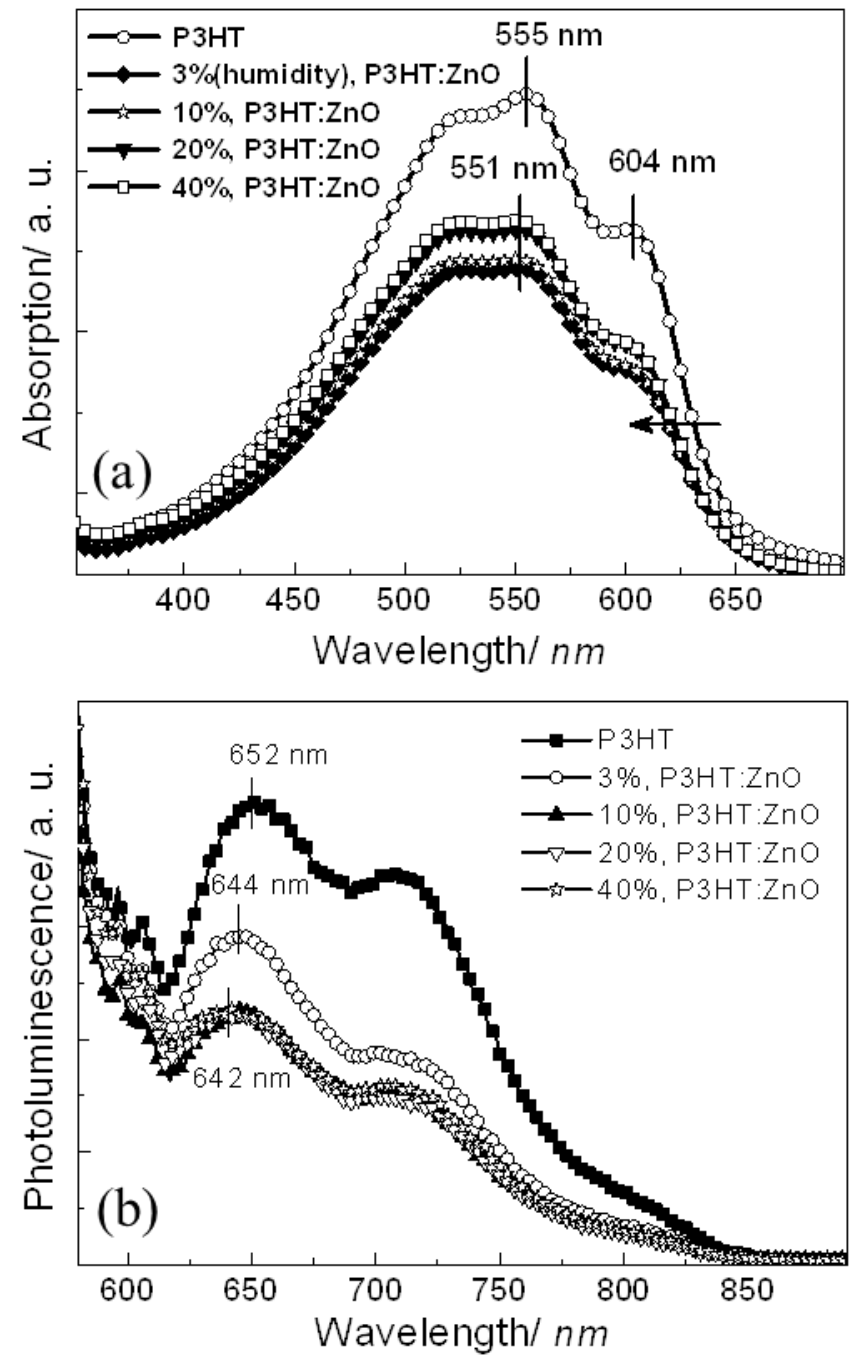

Figure 1. (a) UV-Vis absorption spectra, and (b) Photoluminescence for P3HT, and P3HT:ZnO spin-casted in $3 \%, 10 \%, 20 \%$, and $40 \%$ humidity.

Having understood the effect of $\mathrm{ZnO}$ formation on the structure of the $\mathrm{D}$ phase, attention is now turned towards the effect of humidity on exciton dissociation and charge trapping in the blend. One possible route towards investigating both exciton dissociation as well as radiative recombination is through PL spectroscopy. Representative spectra obtained for the rrP3HT:ZnO blends prepared under different humidity levels and compared to the PL spectrum 
of virgin rr-P3HT are given in Figure 1 (b). As in the case of the absorption spectrum, the PL spectrum of rr-P3HT is expected to display a low wavelength emission feature as well as two additional vibronic features at higher wavelengths. Through comparison of the PL emission spectra of the $\mathrm{ZnO}$ incorporated rr-P3HT with pristine rr-P3HT, it is observed that the inclusion of the $\mathrm{ZnO}$ nanostructures leads to a decrease in the PL intensity for the emission features of rr-P3HT with increasing relative humidity. While the PL quenching can be attributed as being due to an efficient dissociation of excitons into free electrons and holes at the polymer - inorganic nanostructure interface, it is also noted that such free charges could in principle recombine non-radiatively resulting in quenching of the rr-P3HT PL. In addition to the above mentioned decrease in PL intensity, a blue shift of the rr-P3HT emission peaks is also observed upon the introduction of $\mathrm{ZnO}$ nanostructures into rr-P3HT. Although a blue shift was also observed through optical absorption spectroscopy, the blue shift of the vibronic features in the PL spectra is more noticeable in comparison to the vibronic features in the absorption spectra upon the addition of $\mathrm{ZnO}$ to the $\mathrm{D}$ phase. This suggests the possibility of an additional broad emission peak that can lead to an apparent shift of the rr-P3HT emission peaks.

The room temperature PL spectrum of $\mathrm{ZnO}$ excited at energies above its band edge absorption are known to display two emission peaks: a near UV emission peak due to the recombination of electrons due to band edge excitation and a broad green emission in the wavelength region of $450-500 \mathrm{~nm} .{ }^{[9]}$ The PL emission maps in the visible wavelength region for thin films of $\mathrm{ZnO}$ nanostructures observed under different excitation wavelengths are given in Figure 2. As noted from the emission maps for $\mathrm{ZnO}$ prepared through the exposure of $\mathrm{DEZ}$ to different levels of humidity, the $\mathrm{ZnO}$ nanostructures display a green emission in the wavelength region of $400-700 \mathrm{~nm}$. As such, the observed blue shift in the rr-P3HT emission for the hybrid nanostructure is more than likely due to this broad green emission from $\mathrm{ZnO}$. 


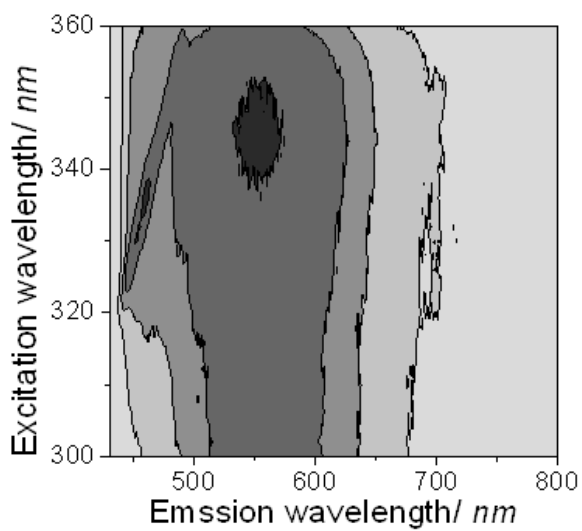

(a)
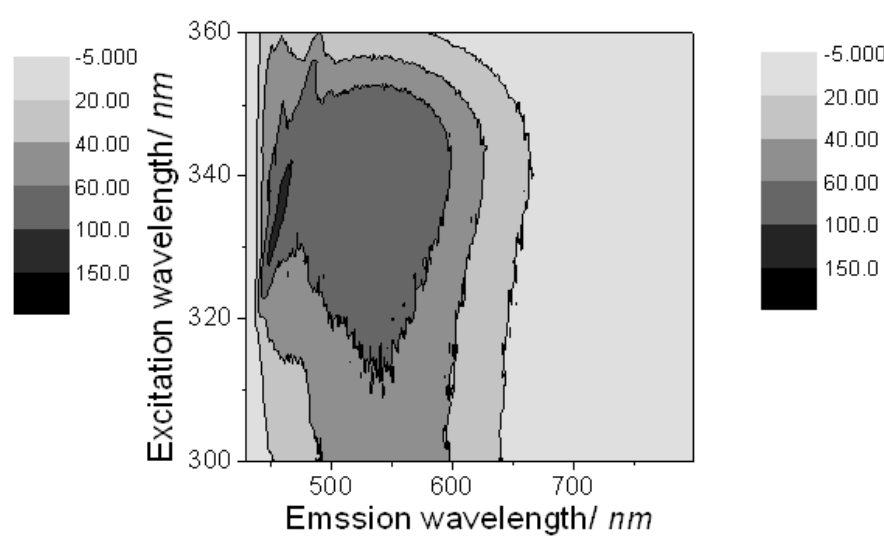

(b)

Figure 2. The mapping of photoluminescence for $\mathrm{ZnO}$ films spin-casted in $3 \%$ (a) and $40 \%$ (b) humidity on $\mathrm{Si}$ substrate.

Despite being frequently reported in the scientific litereature, there has been very little consensus on the origin of the $\mathrm{ZnO}$ green emission with oxygen vacancies or zinc interstitials being attributed as the possible causes for this emission. ${ }^{[9]}$ Although the defect type related to this emission is less clear, work reported by Djurišić et al. ${ }^{[26]}$ as well as by Norberg and Gamelin $^{[27]}$ has located its origin to the surface of the $\mathrm{ZnO}$ nanocrystals. The presence of defect states at the surface of $\mathrm{ZnO}$ nanostructures that act as (radiative) trap sites for electrons can lead to a high series resistance and low short circuit current and hence poor device efficiencies for the rr-P3HT:ZnO hybrid structure. However, as the green emission of $\mathrm{ZnO}$ prepared under a relative humidity of $40 \%$ is observed to be lower than that of the $\mathrm{ZnO}$ nanocrystals prepared under a relative humidity of $3 \%$, it can be inferred that the surface area of the $\mathrm{ZnO}$ nanostructures which creates defect states is reduced under higher relative humidity. As will be discussed later, this explanation is in agreement with the enhanced photovoltaic response of rr-P3HT:ZnO with increasing humidity level.

In order to analyze the effect of humidity (and in turn the surface defects of $\mathrm{ZnO}$ nano structure) on the PV device performance, hybrid photovoltaic devices consisting of rrP3HT:ZnO active layers prepared under different relative humidity values ranging from 3 - 
$40 \%$ were studied. The current density (J) - Voltage (V) characteristics and the related device parameters (open circuit voltage $\left(\mathrm{V}_{\mathrm{oc}}\right)$, short circuit current density $\left(\mathrm{J}_{\mathrm{sc}}\right)$, Fill Factor $(\mathrm{FF})$ and the device efficiency) under exposure to different levels of relative humidity are recorded in Figure 3 and Table 1 respectively.

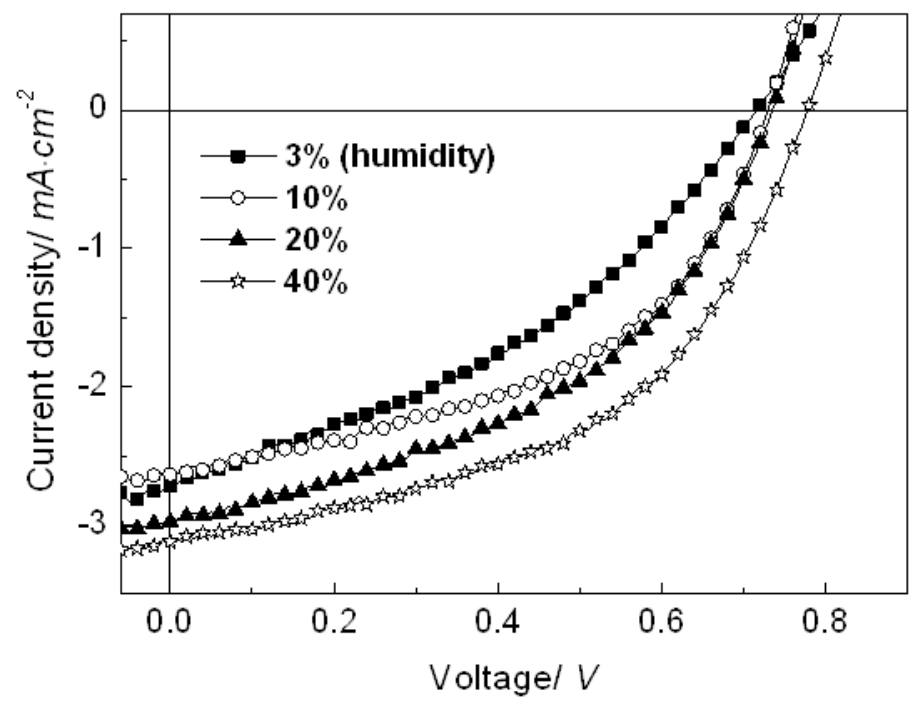

Figure 3. Current density/voltage (J-V) characteristics of the best P3HT:ZnO spin-casted in $3 \%$ (filled squre), $10 \%$ (open circle), $20 \%$ (filled triangle), and $40 \%$ (open star) humidity under illumination with AM $1.5 \mathrm{G}$ simulated solar light.

Table 1. Fundamental PV cell parameters for the hybrid devices fabricated from P3HT:ZnO spin-cast at different humidity levels with a $\mathrm{TiO}_{\mathrm{X}}$ interfacial layer

\begin{tabular}{ccccc}
\hline $\begin{array}{c}\text { Humidity } \\
(\%)\end{array}$ & $\begin{array}{c}\mathbf{V}_{\mathbf{O C}} \\
(\mathrm{V})\end{array}$ & $\begin{array}{c}\mathbf{J}_{\mathrm{SC}} \\
\left(\mathrm{mAcm}^{-2}\right)\end{array}$ & $\begin{array}{c}\mathbf{F F} \\
(\boldsymbol{\%})\end{array}$ & $\begin{array}{c}\text { Efficiency } \\
(\boldsymbol{\%})\end{array}$ \\
\hline 3 & 0.715 & 2.71 & 37.1 & 0.72 \\
10 & 0.730 & 2.64 & 47.4 & 0.91 \\
20 & 0.735 & 2.98 & 44.8 & 0.98 \\
$\mathbf{4 0}$ & $\mathbf{0 . 7 8 0}$ & $\mathbf{3 . 1 2}$ & $\mathbf{4 8 . 8}$ & $\mathbf{1 . 1 9}$
\end{tabular}

Table 1 shows an increase in the device performance parameters as the relative humidity is increased. As was previously observed through the PL spectra, an increase in the moisture 
content leads to a reduction in (radiative) surface trap states in the $\mathrm{ZnO}$ nanostructure which was attributed to a reduction in the surface area of the $\mathrm{ZnO}$ phase. While the reduction in the surface area of $\mathrm{ZnO}$ can be detrimental to the exciton dissociation process, it is beneficial in reducing the radiative recombinations that can occur at the surface of $\mathrm{ZnO}$ following the exciton dissociation. Further investigations carried out at humidity levels higher than those discussed above (Table S4) indicates $40 \%$ as the moisture content required for optimum device performance under the conditions used. This observation is in agreement with the reduction in exciton dissociation as a result of lower interfacial area between rr-P3HT and $\mathrm{ZnO}$. However, it is also noted here that the $\mathrm{J}_{\mathrm{sc}}$ observed for the P3HT:ZnO PVs are lower compared to bulk heterojunction devices with small molecule acceptors. ${ }^{[28]}$ This observation suggests that recombination of dissociated charges is still considerable even under the optimum humidity level.

In conclusion, the performance of blends of rr-P3Ht and $\mathrm{ZnO}$ has been analysed through optical and electrical techniques. The performances of these devices were observed to be governed by the humidity level employed for formation of the $\mathrm{ZnO}$ phase. While a low humidity level is expected to lead to more surface defect sites on the $\mathrm{ZnO}$ nanostructure, a higher humidity level leads to less interfacial area between the organic $\mathrm{D}$ and $\mathrm{ZnO}$ resulting in less exciton dissociation. Investigations carried out on the photovoltaic device performances of hybrid thin films prepared under different humidity levels indicate $40 \%$ to be the optimum value at which charge recombination at the surface is sufficiently minimised while allowing for efficient exciton dissociation pointing to the directions which help in achieving efficient devices with controlled surface defect states.

\section{Experimental}


Materials: Regioregular P3HT (weight average moelcular weight, $\mathrm{Mw}=43600 \mathrm{~g} \mathrm{~mol}^{-1}$ and regioregularity $=95.6 \%$; Merck Chemicals) and diethyl zinc $(1.1 \mathrm{M}$ in toluene; Sigma Aldrich) were used as recieved.

Solution preperation and device fabrication: rr-P3HT (14.3 mg) a $0.4 \mathrm{M}$ diethylzinc solution (2.5 ml) prepared by mixing $0.9 \mathrm{ml}$ of a $1.1 \mathrm{M} \mathrm{DEZ} \mathrm{in} \mathrm{toluene} \mathrm{with} 1.6 \mathrm{ml}$ of tetrahydrofuran were added to chlorobenzene and stirred overnight. Photovoltaic devices were fabricated on ITO coated glass $($ Lumtec, Sheet resistance $=15 \Omega / \square)$ that had been previously cleaned with acetone and methanol in an ultrasonic bath and subsequently treated with an oxygen plasma. Poly(3,4-ethylenedioxythiophene) poly(styrenesulfonate) (PEDOT:PSS) (Baytron) was spin coated at $5000 \mathrm{rpm}$ for $60 \mathrm{~s}$ and then annealed at $140{ }^{\circ} \mathrm{C}$ for $15 \mathrm{~min}$ to form the hole transport layer. A $160 \mathrm{~nm}$ thick rr-P3HT:ZnO active layer was then spin casted (spin speed of $600 \mathrm{rpm}$ for $60 \mathrm{~s}$ ) on the PEDOT:PSS layer. During the spin coating process for the rrP3HT:ZnO layer, the relative humidity within the spin coater was maintained at 3, 10, 20, and $40 \%$ by controlling the nitrogen flow within the spin coater. Upon drying for $30 \mathrm{~min}$ at a relative humidity of $\sim 40 \pm 5 \%$, the samples were annealed at a $120{ }^{\circ} \mathrm{C}$ on for a further 30 min to remove solvents. $\mathrm{A}_{\mathrm{TiO}}$ precursor solution prepared using the technique described by Park et al. ${ }^{[29]}$ was then spin coated at $2000 \mathrm{rpm}$ for $40 \mathrm{sec}$ on the rr-P3HT:ZnO layer in nitrogen and subsequently annealed at $120^{\circ} \mathrm{C}$ after aging for 30 minutes. The Spin coating of PEDOT:PSS, rr-P3HT:ZnO blend and the $\mathrm{TiO}_{\mathrm{X}}$ precursor solution, as well $\mathrm{s}$ the thermal annealing and aging processes were carried out inside a fume cupboard. Finally, a $90 \mathrm{~nm}$ thick Al metal cathode was deposited by thermal evaporation at a base pressure of $\sim 3 \times 10^{-6}$ mbar. The PV characterisation was performed with an AM 1.5G simulated irradiation using a $300 \mathrm{~W}$ Oriel simulator, calibrated to $100 \mathrm{~mW} / \mathrm{cm}^{2}$ with a Newport reference solar cell. A Keithley 2425 source meter was utilised as the electronic load. 
Optical absorption and photoluminescence (PL) spectroscopy: thin films of rr- P3HT thin films ( $95 \pm 5 \mathrm{~nm}$ thickness) and rr-P3HT:ZnO blends $(160 \mathrm{~nm})$ were spin coated on top of glass (UV-Visible absorption) and Si (PL) under different humidity conditions for P3HT and P3HT:DEZ solutions. For PL mapping, ZnO films were spin-coated on Si substrate in $3 \%$ and $40 \%$ humidity. The absorption and PL spectra were obtained from Varian Cary 5000 UV-Visible and Cary Eclipse spectrophotometer, respectively.

\section{Acknowledgements}

This work is based on a project which is funded by E.ON AG, as part of the E.ON International research Initiative. The authors would also like to thank Michail Beliatis and Dinesha Dabera for useful discussions.

\section{References}

[1] K. Lee, S. H. Park, A. Roy, S. Beaupre, S. Cho, N. Coates, J. S. Moon, D. Moses, M. Leclerc, A. J. Heeger, Nat. Photonics, 2009, 3, 297.

[2] G. Li, V. Shrotriya, J. S. Huang, Y. Yao, T. Moriarty, K. Emery, Y. Yang, Nat. Mater., $\mathbf{2 0 0 5}, 4,864$.

[3] H-Y Chen, J. Hou, S. Zhang, Y. Liang, G. Yang, Y. Yang, L. Yu, Y. Wu, G. Li, Nat. Photonics, 2009, 3, 649.

[4] P. A. Troshin, H. Hoppe, A. S. Peregudov, M. Egginger, S. Shokhovets, G. Gobsch, N. S. Sariciftci, V. F. Razumov, Chemsuschem, 2011, 4, 119.

[5] G. Yu, J. Gao, J. C. Hummelen, F. Wudl, A. J. Heeger, Science, 1995, 270, 1789.

[6] P. Sonar, J. P. F. Lim, K. L. Chan, Energ. Environ. Sci., 2011, 4, 1558. 
[7] S. D. Oosterhout, M. M. Wienk, S. S. van Bavel, R. Thiedmann, L. J. A. Koster, J. Gilot, J. Loos, V. Schmidt, R. A. J. Janssen, Nat. Mater, 2009, 8, 818.

[8] A. C. Arango, L. R. Johnson, V. N. Bliznyuk, Z. Schlesinger, S. A. Carter, H. H. Horhold, Adv. Mater., 2000, 12, 1689.

[9] A. B. Djurisic, Y. H. Leung, Small, 2006, 2, 944.

[10] W. J. E. Beek, M. M. Wienk, R. A. J. Janssen, Adv. Mater. 2004, 16, 1009.

[11] E. A. Meulenkamp, J. Phys. Chem. B, 1998, 102, 5566.

[12] S. Cho, J. H. Seo, S. H. Park, S. Beaupre, M. Leclerc, A. J. Heeger, Adv. Mater. 2010, $22,1253$.

[13] S-S Li, Y-Y Lin, W-F Su, C-W Chen, IEEE J. Sel. Top. Quant, 2010, 16, 1635.

[14] J. Boucle, H. J. Snaith, N. C. Greenham, J. Phys. Chem. C, 2010, 114, 3664.

[15] H. M. P. Wong, P. Wang, A. Abrusci, M. Svensson, M. R. Andersson, N. C. Greenham, J. Phys. Chem. C, 2007, 111, 5244.

[16] S. J. Wu, J. H. Li, Q. D. Tai, F. Yan, J. Phys. Chem. C, 2010, 114, 21873.

[17] W. J. E. Beek, L. H. Slooff, M. M. Wienk, J. M. Kroon, R. A. J. Janssen, Adv. Funct. Mater. 2005, 15, 1703.

[18] D. J. D. Moet, L. J. A. Koster, B. de Boer, P. W. M. Blom, Chem. Mater., 2007, 19, 5856.

[19] S. D. Oosterhout, L. J. A. Koster, S. S. van Bavel, J. Loos, O. Stenzel, R. Thiedmann, V. Schmidt, B. Campo, T. J. Cleij, L. Lutzen, D. Vanderzande, M. M. Wienk, R. A. J. Janssen, Adv. Energy. Mater., 2011, 1, 90.

[20] S. D. Oosterhout, M. M. Wienk, M. Al-Hashimi, M. Heeney, R. A. J. Janssen, J. Phys. Chem. C 2011, 115, 18901.

[21] T. Andelman, Y. Y. Gong, M. Polking, M. Yin, I. Kuskovsky, G. Neumark, S. O'Brien, J. Phys. Chem. B, 2005, 109, 14314. 
[22] H. E. Unalan, P. Hiralal, N. Rupesinghe, S. Dalal, W. I. Milne, J. A. J. Amaratunga, IOP Nanotech., 2008, 19, 255608.

[23] T. A. Chen, X. M. Wu, R. D. Rieke, J. Am. Chem. Soc., 1995, 117, 233.

[24] S. I. Khondaker, T. Pal, M. Arif, IOP Nanotechnology, 2010, 21.

[25] Y. Yang, G. Li, Y. Yao, H. Yang, V. Shrotriya, G. Yang, Adv. Funct. Mater., 2007, 17, 1636.

[26] A. B. Djurisic, W. C. H. Choy, V. A. L. Roy, Y. H. Leung, C. Y. Kwong, K. W. Cheah, T. K. G. Rao, W. K. Chan, H. T. Lui, C. Surya, Adv. Funct. Mater., 2004, 14, 856.

[27] N. S. Norberg, D. R. Gamelin, J. Phys. Chem. B, 2005, 109, 20810.

[28] N. A. Nismy, K. D. G. I. Jayawardena, A. A. D. T. Adikaari, S. R. P. Silva, Adv. Mater., 2011, 23, 3796.

[29] S. H. Park, A. Roy, S. Beaupre, S. Cho, N. Coates, J. S. Moon, D. Moses, M. Leclerc, K. Lee, A. J. Heeger, Nat. Photonics, 2009, 3, 297. 